\title{
The Importance of a Properly Represented Stratosphere for Northern Hemisphere Surface Variability in the Atmosphere and the Ocean ${ }^{\mathscr{O}}$
}

\author{
SABINE HAASE \\ GEOMAR Helmholtz Centre for Ocean Research Kiel, Kiel, Germany \\ KATJA MATTHES AND MoJiB LATIF \\ GEOMAR Helmholtz Centre for Ocean Research Kiel, and Christian-Albrechts-Universität zu Kiel, Kiel, Germany \\ NOUR-EDDINE OMRANI \\ Geophysical Institute, University of Bergen, and Bjerknes Centre for Climate Research, Bergen, Norway
}

(Manuscript received 3 August 2017, in final form 18 July 2018)

\begin{abstract}
Major sudden stratospheric warmings (SSWs) are extreme events during boreal winter, which not only impact tropospheric weather up to three months but also can influence oceanic variability through wind stress and heat flux anomalies. In the North Atlantic region, SSWs have the potential to modulate deep convection in the Labrador Sea and thereby the strength of the Atlantic meridional overturning circulation. The impact of SSWs on the Northern Hemisphere surface climate is investigated in two coupled climate models: a stratosphereresolving (high top) and a non-stratosphere-resolving (low top) model. In both configurations, a robust link between SSWs and a negative NAO is detected, which leads to shallower-than-normal North Atlantic mixed layer depth. The frequency of SSWs and the persistence of this link is better captured in the high-top model. Significant differences occur over the Pacific region, where an unrealistically persistent Aleutian low is observed in the low-top configuration. An overrepresentation of SSWs during El Niño conditions in the low-top model is the main cause for this artifact. Our results underline the importance of a proper representation of the stratosphere in a coupled climate model for a consistent surface response in both the atmosphere and the ocean, which, among others, may have implications for oceanic deep convection in the subpolar North Atlantic.
\end{abstract}

\section{Introduction}

During winter, the polar stratosphere is characterized by a westerly wind jet, the so-called polar night jet (PNJ), which marks the edge of the stratospheric polar vortex. Variability of the stratospheric polar vortex is determined by the breaking and dissipation of planetary-scale waves, which are generated in the troposphere and propagate upward into the stratosphere during moderate westerly wind regimes (Charney and Drazin 1961). Strong wave forcing from the troposphere can decelerate the PNJ or even reverse it, thereby leading to a breakdown of the normal stratospheric winter circulation. These

Supplemental information related to this paper is available at the Journals Online website: https://doi.org/10.1175/JCLI-D-17-0520.s1.

Corresponding author: Sabine Haase, shaase@geomar.de stratospheric extreme events are termed major sudden stratospheric warmings (SSWs; Scherhag 1952). They are prominent examples of stratosphere-troposphere coupling in the Northern Hemisphere (NH), where they occur in two of every three years. SSWs are characterized by mid- to high-latitude stratospheric temperature and zonal wind anomalies propagating downward ${ }^{1}$ within a

\footnotetext{
${ }^{1}$ Strictly speaking, anomalies that are caused by wave-mean flow interaction at a certain level in the atmosphere do not physically propagate downward but lead to a different state of the background wind that influences wave propagation and dissipation. Thereby, waves are forced to penetrate to successively lower altitudes, depositing easterly momentum there, which leads to a signature that is commonly described as a downward propagation or descent of anomalies. We also use this terminology to illustrate the downward influence of SSWs, asking the reader to keep in mind that the processes of stratosphere-troposphere coupling are manifold and more complicated than a simple descent of anomalies.
} 
few days and persisting for more than 60 days in the lower stratosphere and troposphere (Baldwin and Dunkerton 2001). They project onto the negative phase of the northern annular mode (NAM) or Arctic Oscillation (AO) at the surface (Baldwin and Dunkerton 1999, 2001; Kuroda and Kodera 1999), which is the dominant mode of $\mathrm{NH}$ geopotential height $(\mathrm{GPH})$ variability in winter (Thompson and Wallace 1998, 2000). The tropospheric response to SSWs is zonally asymmetric, with stronger anomalies over the North Atlantic region as compared to the North Pacific (Hitchcock and Simpson 2014). The response can thus be well described by the negative phase of the North Atlantic Oscillation (NAO; Walker and Bliss 1932; Hurrell 1995), which is characterized by an equatorward shift of the tropospheric Atlantic jet, positive surface air temperature anomalies over the Labrador Sea region, and negative surface air temperature anomalies over northern Eurasia (Hurrell et al. 2003; Hitchcock and Simpson 2014; Kidston et al. 2015). A statistical connection between the phase of the NAO and SSWs was suggested by Baldwin et al. (1994) and Perlwitz and Graf (1995). Since SSWs influence the tropospheric circulation on time scales from a few days to a few months (Baldwin and Dunkerton 2001), they are particularly important for the representation of surface climate variability and have a large potential to improve (sub-) seasonal weather forecast and seasonal prediction in the extratropics, as suggested by Thompson et al. (2002) and Baldwin et al. (2003). It was shown by Sigmond et al. (2013) that a good representation of the stratosphere enhances predictability in a seasonal forecast system.

The preconditioning, life cycle, and tropospheric response to different types of SSWs have been studied extensively in the last decades (e.g., Perlwitz and Graf 1995; Limpasuvan et al. 2004; Charlton and Polvani 2007; Kodera et al. 2016). Several mechanisms have been proposed for the downward propagation of stratospheric circulation anomalies into the troposphere, that is, stratosphere-troposphere coupling. These mechanisms involve the nonlocal downward control of the tropospheric circulation by stratospheric wave forcing (Haynes et al. 1991) or potential vorticity change (Ambaum and Hoskins 2002; Black 2002), wave reflection (Perlwitz and Harnik 2003), and refraction (Hartmann et al. 2000; Limpasuvan and Hartmann 2000) as well as eddy feedbacks in the troposphere (Song and Robinson 2004; Kunz and Greatbatch 2013).

Blocking events over the Atlantic, the Pacific, and over the Eurasian continent as well as a strengthening of the Aleutian low and a positive pressure anomaly over Scandinavia have been shown to act as precursors to SSWs (Limpasuvan et al. 2004; Martius et al. 2009; Kolstad and Charlton-Perez 2011; Bancalá et al. 2012;
Lehtonen and Karpechko 2016). The Aleutian low is known to be influenced by the El Niño-Southern Oscillation (ENSO; Philander et al. 1985) and Pacific decadal oscillation (PDO; Mantua et al. 1997). During the ENSO warm phase (El Niño), positive sea surface temperature (SST) anomalies in the equatorial Pacific cold tongue region coincide with negative SST anomalies in the central North Pacific (Trenberth 1997). At the same time, an enhanced Aleutian low is observed (Horel and Wallace 1981; Trenberth et al. 1998). It interferes constructively with the climatological stationary wave pattern, which is dominated by zonal wavenumber 1 (wave-1). This constructive or positive interference was shown to enhance upward planetary wave propagation, leading to a disturbance of the polar stratosphere after El Niño events (Manzini et al. 2006; Taguchi and Hartmann 2006; Ineson and Scaife 2009; Barriopedro and Calvo 2014). A similar pathway as during El Niño has been found for the positive phase of the PDO (Jadin et al. 2010; Hurwitz et al. 2012; Woo et al. 2015; Kren et al. 2016). Whereas the impact of ENSO on the climatological mean state of the polar vortex is well agreed on in the literature, ENSO's influence on the occurrence of stratospheric extreme events, such as SSWs, which determine stratospheric variability, is not. Butler and Polvani (2011) showed that stratospheric polar temperature is positively correlated with the central equatorial Pacific SST (Niño-3.4 index), but the occurrence of SSWs is not. They find in reanalysis data the same probability for SSWs to occur during El Niño as La Niña winters. In neutral ENSO winters, the probability for SSW occurrence is only half as high.

Obviously, the Pacific Ocean is an interesting region with respect to the preconditioning of SSWs. It is less clear whether SSWs feed back on the Pacific Ocean. The literature suggests a stronger influence on the Atlantic region compared to the Pacific region (e.g., Garfinkel et al. 2013; Hitchcock and Simpson 2014). Here, we take a closer look at this issue. We explicitly consider the feedback of SSWs on the Pacific Ocean, which to our knowledge has not been addressed so far. In fact, previous studies on the effect of stratospheric circulation anomalies on the ocean focused solely on the Atlantic (Reichler et al. 2012; Manzini et al. 2012). Reichler et al. (2012) studied the connection between long-lasting extreme stratospheric polar vortex episodes and deep oceanic temperatures and the Atlantic meridional overturning circulation (AMOC). They found by means of a non-stratosphere-resolving (low top) global climate model that the AMOC maximum lags such stratospheric episodes by 8 to 10 years. Manzini et al. (2012) investigated the low-frequency effects of stratospheretroposphere-ocean coupling in a stratosphere-resolving 
(high top) global climate model for 20 -yr periods, which were dominated by either weak or strong polar vortex states. They also report a statistically significant correlation between low-frequency vortex variability and the AMOC. In their study, the AMOC lags by three years. Reichler et al. (2012) compare their low-top model results to a number of high- and low-top models participating in phase 5 of the Coupled Model Intercomparison Project (CMIP5) and find a stronger surface response in the high-top models. However, the AMOC response does not differ significantly between low- and hightop models.

Boville (1984) already pointed out that inaccuracies in the representation of the stratospheric PNJ in a climate model would affect the propagation of planetary waves and thereby the tropospheric circulation. The effect of the position of the model lid on planetary wave propagation was further studied by Shaw and Perlwitz (2010). They detected unrealistically strong wave reflection at the lower model lid particularly for wave-1, which they could reduce by parameterizing the effect of gravity waves in the low-top model. In a low- versus high-top model comparison [Community Atmosphere Model, version 3.0 (CAM3.0), vs Whole Atmosphere Community Climate Model, version 3 (WACCM3)], Sassi et al. (2010) attributed differences between the models' tropospheric circulations to differences in the zonal-mean states of their respective stratospheres. The differences in the stratosphere were found to result from strong planetary-scale wave reflection close to the model lid in the low-top version (CAM3.0). Charlton et al. (2013) investigating CMIP5 models showed that stratospheric variability is much better represented in high-top models in comparison to low-top models, which has significant effects on the frequency of SSWs and persistence of their tropospheric impact. Lee and Black (2015) point out that the tropospheric response to extreme stratospheric polar vortex anomalies is very similar for high- and low-top models despite an anomalously weak vertical dynamical coupling in low-top models.

As pointed out above, previous studies agree on the fact that high-top models better represent stratospheric variability than low-top models, as they have a better capability to represent stratospheric dynamics, which greatly involves the representation of planetary wave propagation (Boville 1984; Sassi et al. 2010; Shaw and Perlwitz 2010). The degree to which the tropospheric response to extreme stratospheric events differs between models of varying stratospheric representation is not as clear (e.g., Charlton et al. 2013; Lee and Black 2015) and is addressed in detail in this paper. With respect to the oceanic response to extreme stratospheric events, recent studies only considered the Atlantic region (Manzini et al. 2012; Reichler et al. 2012). However, the Pacific Ocean can be influenced by SSWs as well, for example, through the buildup of blocking over the North Pacific due to wave reflection, as recently described by Kodera et al. (2016). A positive sea level pressure (SLP) signal over the North Pacific after SSWs has also been observed by Charlton and Polvani (2007) for vortex split events, whereas no significant response has been found for displacement events. This difference over the North Pacific, however, is not robust among different definitions of split and displacement events (Maycock and Hitchcock 2015). Hence, in contrast to the anomalously deep Aleutian low acting as a precursor to SSWs, there is no clear tendency for an anomalous SLP signal over the Aleutian low region following SSWs. In the Atlantic-European sector, on the other hand, studies agree on the negative NAO response to SSWs irrespective of the warming type (e.g., Limpasuvan et al. 2004; Charlton and Polvani 2007). Here, we study the tropospheric response to major SSWs in the Atlantic as well as in the Pacific sector.

Our focus is not on the low-frequency variability as in Reichler et al. (2012) and Manzini et al. (2012), as the length of our experiments does not allow for an investigation of dependencies on multidecadal time scales. Instead, we investigate how SSWs in early to midwinter [November-January (NDJ)] impact surface wind stress and turbulent heat fluxes and thereby the ocean characteristics in the North Atlantic and North Pacific on monthly to interannual time scales. We restrict the analyses to NDJ SSWs, as these have the largest potential to affect Labrador Sea deep convection that maximizes in March because the subsurface ocean takes up to two months to react to stratospheric events. As an indicator for oceanic deep convection, we use the monthly maximum mixed layer depth (MLD). MLD variability during late boreal winter is an important driver of the AMOC, which has been suggested on the basis of ocean model simulations by Eden and Jung (2001) and Eden and Willebrand (2001) and observations by Latif and Keenlyside (2011). In the Pacific Ocean, which lacks a deep overturning circulation, we do not consider MLD anomalies but investigate the effects of NDJ SSWs on the depth-integrated ocean circulation and SST. Finally, to estimate the role of the representation of the stratosphere for the surface response following NDJ SSWs we use a high-top and low-top model of the same model family. The representation of SSWs and their impacts is influenced by differences in the climatological background state between the models, planetary-scale wave propagation, and the states linked to different ENSO phases. The assessment of these properties is a focus of this study. 
TABLE 1. Model simulation overview. Horizontal resolution and TMS parameterization are adapted to the WACCM setting in CCSM4WSET.

\begin{tabular}{lllcccc}
\hline \hline & \multicolumn{1}{c}{ Model name } & Atmospheric component & Horizontal resolution & Vertical levels & Model top (hPa/km) & Model years \\
\hline High top & CESM1(WACCM) & WACCM4 & $1.9^{\circ} \times 2.5^{\circ}$ & 66 & $5.1 \times 10^{-6} / \sim 140$ \\
Low top & CCSM4-WSET & CAM4 & $1.9^{\circ} \times 2.5^{\circ}$ & 26 & $3.54 / \sim 40$ & 150 \\
\hline
\end{tabular}

The outline of the paper is as follows: In section 2, we introduce the models and methods. The characteristics of SSWs in the models and their effects on the North Atlantic and North Pacific are described in section 3, and reasons for the different model behavior is discussed in section 4. We summarize the main results and present the main conclusions in section 5 .

\section{Data and methods}

\section{a. Model description}

To assess the role of the stratosphere for NH surface climate variability, two climate models are used here: one includes the whole stratosphere up to the lower thermosphere (about $140 \mathrm{~km}$ ), and the other only extends up to the middle stratosphere (about $40 \mathrm{~km}$ ). The two climate models are from the same model family and were developed at the National Center of Atmospheric Research (NCAR). Both NCAR models participate in CMIP5.

The high-top model is the Community Earth System Model, version 1 (CESM1), with WACCM, version 4, as the atmospheric component. This setup is referred to as CESM1(WACCM) by Marsh et al. (2013). The low-top model version is the Community Climate System Model, version 4 (CCSM4; Hurrell et al. 2013), which uses the Community Atmosphere Model, version 4 (CAM4; Neale et al. 2010), as the atmospheric component. Further details on the atmospheric components are given below.

The two climate models incorporate the same ocean, sea ice, and land model components (Hurrell et al. 2013). The ocean [Parallel Ocean Program, version 2 (POP2)] and sea ice model [Community Ice Code, version 4 (CICE4)] have a nominal latitude-longitude resolution of $1^{\circ}$; the ocean model has 60 vertical levels. The land model is the Community Land Model, version 4 (CLM4). A central coupler is used to exchange fluxes between the different components. We refer to Hurrell et al. (2013) and the references therein for further details.

\section{THE ATMOSPHERIC COMPONENTS}

The physics in CAM4 and WACCM are basically the same. However, in WACCM, additional processes needed to represent the meridional circulation and distribution of minor constituents in the middle atmosphere are included, such as the parameterization of nonorographic gravity waves, etc. (Marsh et al. 2013). WACCM additionally employs a turbulent mountain stress (TMS) parameterization, which estimates mountain stress due to unresolved orography (Richter et al. 2010). Including TMS in WACCM substantially improves the frequency of SSWs during NH winter (Richter et al. 2010; Marsh et al. 2013). WACCM is a chemistry climate model and as such incorporates a fully interactive chemistry scheme: the Model for Ozone and Related Chemical Tracers, version 3 (MOZART3; Kinnison et al. 2007).

Here, WACCM is used in its standard configuration with a latitude-longitude resolution of $1.9^{\circ} \times 2.5^{\circ}$. It uses a finite volume dynamical core, has 66 vertical levels with variable spacing, and an upper lid at $5.1 \times 10^{-6} \mathrm{hPa}$ (about $140 \mathrm{~km}$ ) that reaches into the lower thermosphere (Garcia et al. 2007). The same horizontal resolution as in WACCM is used in CAM4. This is different from the CMIP5 version of CCSM4 where the horizontal resolution is higher $\left(0.95^{\circ} \times 1.25^{\circ}\right)$ and hence orography better resolved. To account for the lower horizontal resolution in the CAM4 version used here, we include the TMS parameterization from WACCM. This setting was also used in Marsh et al. (2013) and is referred to as the WACCM setting of CCSM4 (CCSM4-WSET). CAM4 has 26 vertical levels and an upper lid at $3.54 \mathrm{hPa}$ (about $40 \mathrm{~km}$ ). The 18 tropospheric levels below $100 \mathrm{hPa}$ are identical in WACCM and CAM4. In the following, we will refer to the CESM1(WACCM) simulation as the high-top simulation and to the CCSM4WSET simulation as the low-top simulation. A summary of the model setups is given in Table 1 .

Both the high-top and low-top model configuration use the CMIP5 preindustrial control settings and a 150 -yr-long simulation is performed with each model. Greenhouse gases (GHGs) and ozone depleting substances (ODSs) are held constant at 1850 levels. Solar variability and volcanic aerosols are not included. The models are not capable of generating the quasi-biennial oscillation (QBO), and QBO nudging was not applied, either. The model output was deseasonalized by subtracting long-term daily or monthly climatological means and the residuals are referred to as anomalies.

\section{b. Methods}

We adopt the SSW definition of the World Meteorological Organization (WMO; e.g., Andrews et al. 1987) 
and concentrate on SSWs occurring in NDJ. Major SSWs are defined to occur when the zonal-mean zonal wind between November and April reverses sign at $60^{\circ} \mathrm{N}$ and $10 \mathrm{hPa}$, that is, changes from westerly to easterly. The central date (or onset) of the event is the first day with a wind reversal. We also include the temperature criterion in the definition, namely, the zonal-mean temperature difference between $60^{\circ} \mathrm{N}$ and the pole at $10 \mathrm{hPa}$ has to be positive for at least five consecutive days. To avoid double counting of events, one central date cannot be followed by another one within a 20-day period (Charlton and Polvani 2007). To exclude final warmings, the described criterion only leads to the identification of a SSW if the westerly wind recovers for at least 10 consecutive days prior to 30 April (Charlton and Polvani 2007) and exceeds a threshold of $5 \mathrm{~m} \mathrm{~s}^{-1}$ (Bancalá et al. 2012). With this method, we identify 41 (22) NDJ SSWs and 30 (24) SSWs in February-April (FMA) in the high-top (low-top) model. If not stated otherwise, FMA SSWs and final warmings are excluded from the analysis. The results are robust and the same conclusions can be drawn when the whole winter season is considered (not shown).

For comparison we use the 40-yr and interim European Centre for Medium-Range Weather Forecasts Re-Analysis products [ERA-40 (Uppala et al. 2005) and ERA-Interim (Dee et al. 2011)] combined into one dataset. Following Blume et al. (2012), the datasets were merged in 1979, in our case on 1 April 1979. The combined dataset, referred to as "ERA" hereafter, resolves the stratosphere up to $1 \mathrm{hPa}$ and spans the period from 1958 to 2015.

Atmospheric and oceanic variability linked to SSWs are displayed in the form of composites for selected variables before, during, and after SSW onset. We use monthly data in most analyses as ocean variables are only available with monthly resolution. Monthly data are considered appropriate for assessing the ocean response to the atmospheric forcing. The month in which the onset of the SSW occurs is termed the central month or month of onset. Statistical significance is tested using a Monte Carlo approach (e.g., von Storch and Zwiers 1999) similar to the methodology used in de la Torre et al. (2012). We used 10000 randomly produced central months to calculate composites. Statistical significance at the $95 \%$ level is reached when the composites exceed the $2.5 \mathrm{nd}$ or 97.5 th percentile of the distribution drawn from the composites.

We used the Niño-3.4 index following the definition by Trenberth (1997) to define the state of ENSO during SSWs. An El Niño (La Niña) is identified when the 5-yr running mean of normalized SST anomaly in the Niño-3.4 region $\left(5^{\circ} \mathrm{N}-5^{\circ} \mathrm{S}, 170^{\circ}-120^{\circ} \mathrm{W}\right)$ exceeds (falls below) a threshold of $0.4(-0.4)$ for six consecutive months or more (including the central month of the
SSW). All other cases are considered as neutral ENSO conditions.

\section{Results}

\section{a. Representation of SSWs}

Figure 1 compares the polar cap temperature anomalies (Figs. 1a,c,e) as well as the zonal-mean zonal wind signals at $60^{\circ} \mathrm{N}$ (Figs. 1b,d,f) for all NDJ SSWs in the high-top (Figs. 1a,b) and low-top model (Figs. 1c,d) from 60 days before to 120 days after the event. The bottom panels (Figs. 1e,f) show the differences between the two simulations. Warming starts at a higher altitude in the high-top model compared to the low-top model. It reaches the lower stratosphere and upper troposphere with a lag of a few days and persists there for about 70 days in the high-top model (Fig. 1a) and for more than 80 days in the low-top model (Fig. 1c). Overall, temperature anomalies occur earlier, are stronger (by up to $10 \mathrm{~K}$ above $5 \mathrm{hPa}$ ), and show a more pronounced descent over time in the high-top model (Fig. 1e). Consistent with the polar cap temperature anomalies, the zonal-mean zonal wind at $60^{\circ} \mathrm{N}$ (Figs. 1b,d,f) depicts a more abrupt, more pronounced, and more persistent wind reversal in the high-top compared to the low-top model. These differences reach down to the surface but with much reduced amplitude (Fig. 1f). Although the low-top model is capable of producing major SSWs, their characteristics differ considerably from those of the high-top model, which is in better agreement with observations [cf. e.g., Fig. 7 in Hansen et al. (2014)].

The SSW frequency in the high-top model (Fig. 2a, blue bars) is very close to the ERA data (gray bars), whereas the low-top model (green bars) underestimates the occurrence of SSWs, especially during December and January. Note that we solely consider preindustrial control runs. The SSW frequency in the high-top model amounts to 0.48 events per winter, in the low-top model to 0.31 events per winter (Fig. 2b), and in the ERA to 0.59 events per winter.

\section{b. Surface connection}

Figure 3 shows the SLP anomalies (color shading) associated with the NDJ SSWs in the high-top (Figs. 3a-d) and low-top (Figs. 3e-h) model for different lags with respect to the month of the SSW onset. Statistically significant SLP anomalies are shown in color. The black contours depict the climatological SLP field simulated in the two models. One month before the onset of the SSWs (lag -1), both the Aleutian low and an anomalous high over Scandinavia, known precursors of SSWs, are 

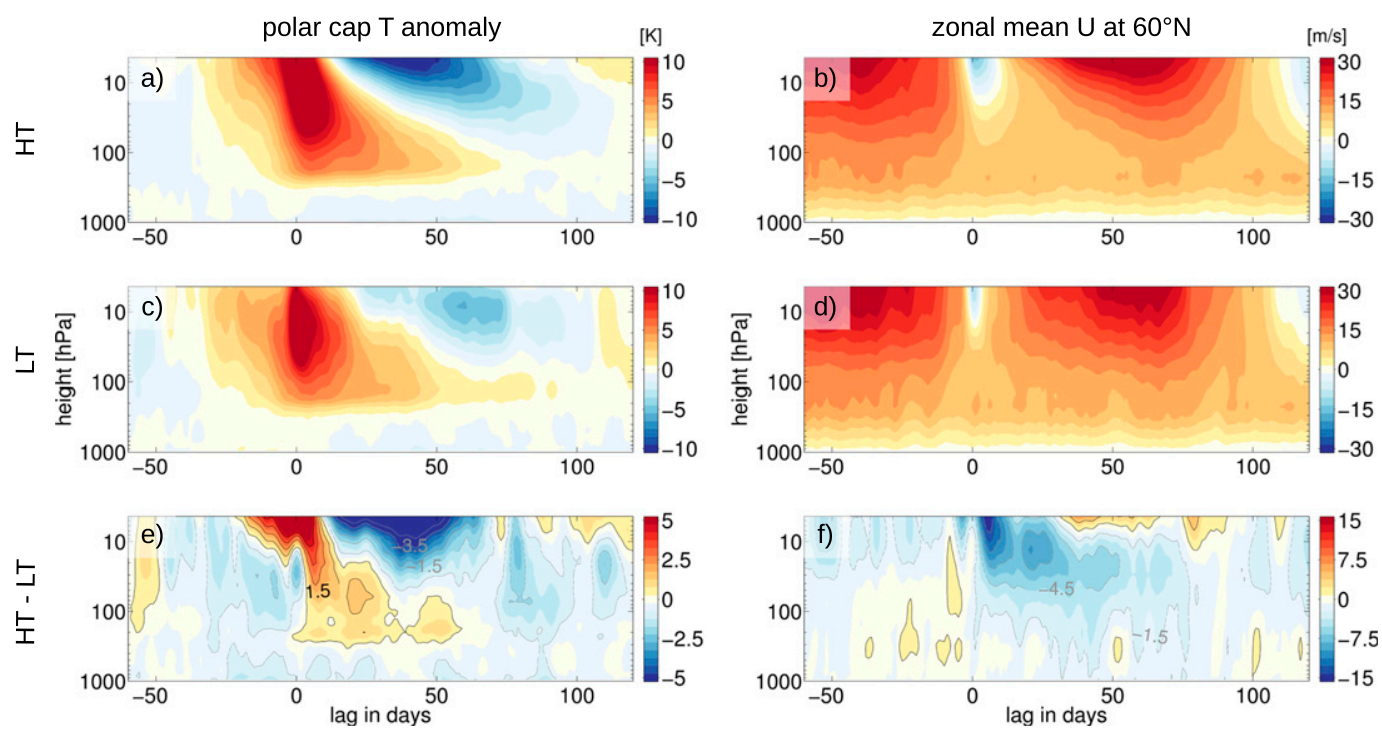

FIG. 1. NDJ SSW composites with respect to the central date (lag 0) in (a),(b) the high-top model, (c),(d) the lowtop model, and (e),(f) the difference between high- and low-top model for polar cap $\left(>60^{\circ} \mathrm{N}\right)$ temperature anomalies in (a), (c), and (e) and zonal-mean zonal wind at $60^{\circ} \mathrm{N}$ in (b), (d), and (f). Temperature anomalies range from -10 to $+10 \mathrm{~K}$ with a shading interval of $1 \mathrm{~K}$ for the individual models and from -5 to $+5 \mathrm{~K}$ with a shading interval of $0.5 \mathrm{~K}$ and a contour interval of $1 \mathrm{~K}$ (negative contours are gray and represent values $\leq-0.5 \mathrm{~K}$; positive contours are black representing values $\geq 0.5 \mathrm{~K}$ ) for the model difference. Zonal-mean zonal wind ranges from -30 to $+30 \mathrm{~m} \mathrm{~s}^{-1}$ with a shading interval of $3 \mathrm{~m} \mathrm{~s}^{-1}$ for the individual models and from -15 to $+15 \mathrm{~m} \mathrm{~s}^{-1}$ with a shading interval of $1.5 \mathrm{~m} \mathrm{~s}^{-1}$ and a contour interval of $3 \mathrm{~m} \mathrm{~s}^{-1}$ (negative contours are gray and represent values $\leq$ $-1.5 \mathrm{~m} \mathrm{~s}^{-1}$; positive contours are black representing values $\geq 1.5 \mathrm{~m} \mathrm{~s}^{-1}$ ) for the model difference.

enhanced in both model configurations. However, the anomalously high SLP over Eurasia is located too far southeast in the high-top model compared to the results from Lehtonen and Karpechko (2016). Its location and amplitude is better captured in the low-top model. At the onset of the SSWs (lag 0), a clear negative NAO pattern starts to develop in both models, with a weakening of the Icelandic low and the Azores high. Over the Pacific, both models still simulate an anomalously strong Aleutian low. One month later (lag +1$)$, both models

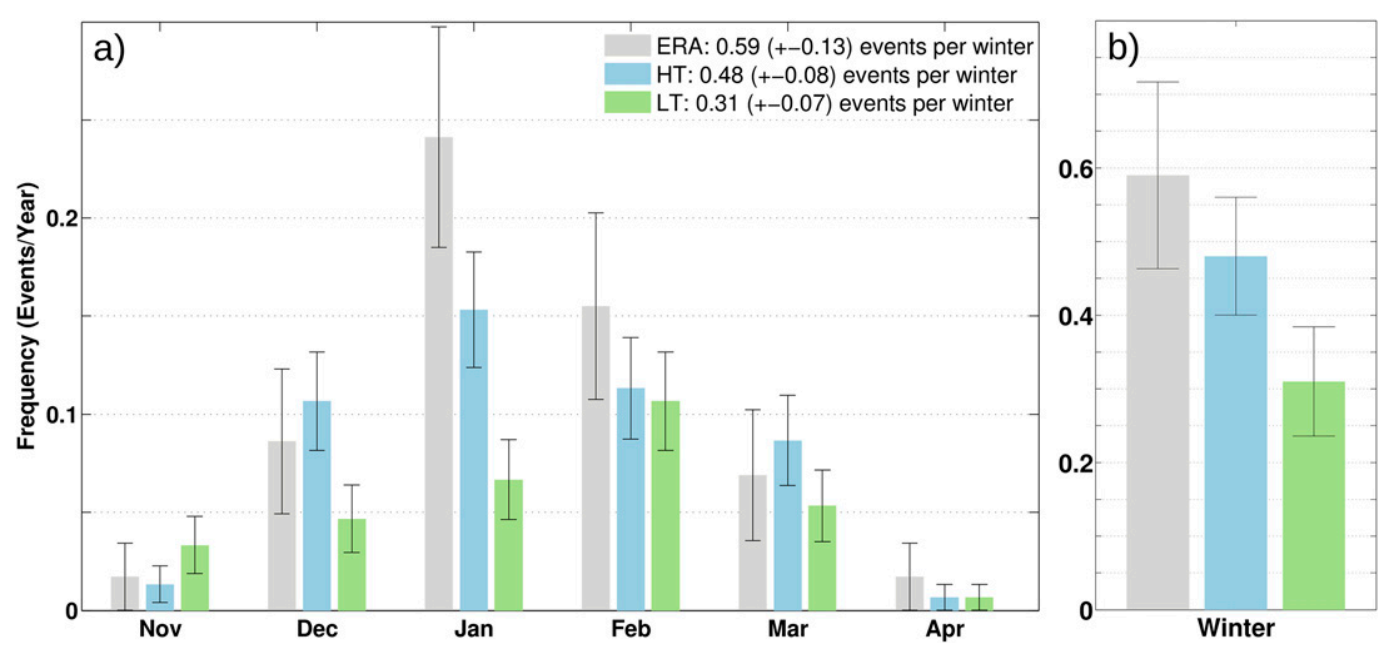

FIG. 2. SSW relative frequency given in events per year for the high-top (blue) and low-top (green) model, as well as for the combined ERA data (gray) for the (a) individual boreal winter months and (b) whole boreal winter season. The error bars indicate the standard error for the monthly frequencies and the $95 \%$ confidence interval, based on the standard error, for the winter mean frequency. 


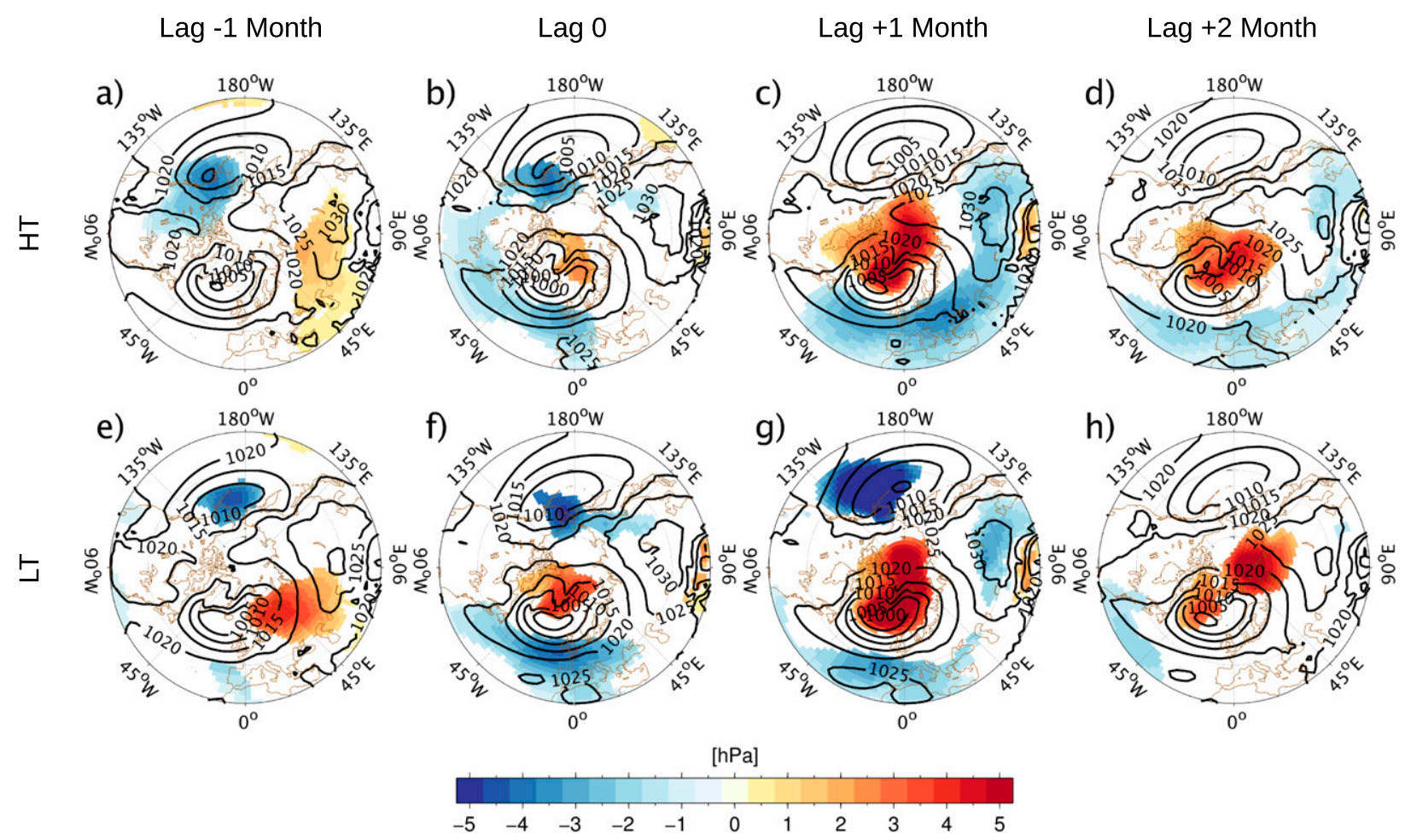

FIG. 3. NDJ SSW composites of SLP anomalies (shading) and the corresponding climatological SLP field (contour lines) in hPa for the (a)-(d) high-top and (e)-(h) low-top model for the month prior to the SSW (lag -1 month), for the month in which the SSW occurs (lag 0), and for the two months following the SSW (lag +1 month and +2 months). The shading interval is $0.5 \mathrm{hPa}$. Colored areas are significant at the $95 \%$ level as computed from a bootstrapping test (see text for details).

feature the strongest negative NAO-like SLP pattern (Figs. 3c,g) but strongly differ over the Pacific sector. While in the low-top model, the negative SLP anomaly over the Aleutian low region is strongest at this time; the high-top model no longer shows a statistically significant signal over the North Pacific. Two months after the onset of the SSWs $(\mathrm{lag}+2)$, the negative NAO-like signal decays in both models but is still more pronounced in the high-top model (Figs. 3d,h). At this time, the anomaly over the North Pacific also disappears in the low-top model.

To summarize, a negative NAO-like SLP anomaly is found in both models, peaking one month after the SSW onset. In contrast to the low-top model, there is a clear restriction of the SLP response to NDJ SSWs to the Atlantic-European sector in the high-top model. The differences between the high-top model and the low-top model are relatively small over the North Atlantic but with the high-top model exhibiting a more persistent SLP response.

\section{c. The Atlantic Ocean}

Consistent with a negative NAO phase, at the beginning of the SSWs (lag 0) easterly wind stress anomalies occur over the midlatitude North Atlantic in both models (arrows in Fig. 4a), indicating a weakening of the prevailing westerlies. The weaker westerlies in conjunction with reduced cold air advection from the northwest drive reduced oceanic heat loss over the Labrador Sea, as indicated by the negative turbulent heat flux anomalies starting at the time of the SSW onset (lag 0$)$ and peaking at lag +1 (Fig. 4a). As expected from the aforementioned results, the persistence of the heat flux anomalies is slightly larger in the high-top model than in the low-top model. We note that the models' Labrador Sea deep convection site is, as in many other climate models, simulated too far south in comparison to observations (Lavender et al. 2002; Heuzé 2017). The link between SSWs, NAO, surface wind stress, and turbulent heat flux agrees well with the findings of Reichler et al. (2012). As their study focused on the impact of strong polar vortex events, they describe anomalies with opposite signs. We also calculated the anomalies associated with strong vortex conditions, and these are of opposite sign compared to those shown in Figs. 3 and 4 (not shown). Reichler et al. (2012), focusing on a low-top model simulation, also compared a number of low-top and high-top CMIP5 models, and, consistent 
a) Heat Flux \& Wind Stress

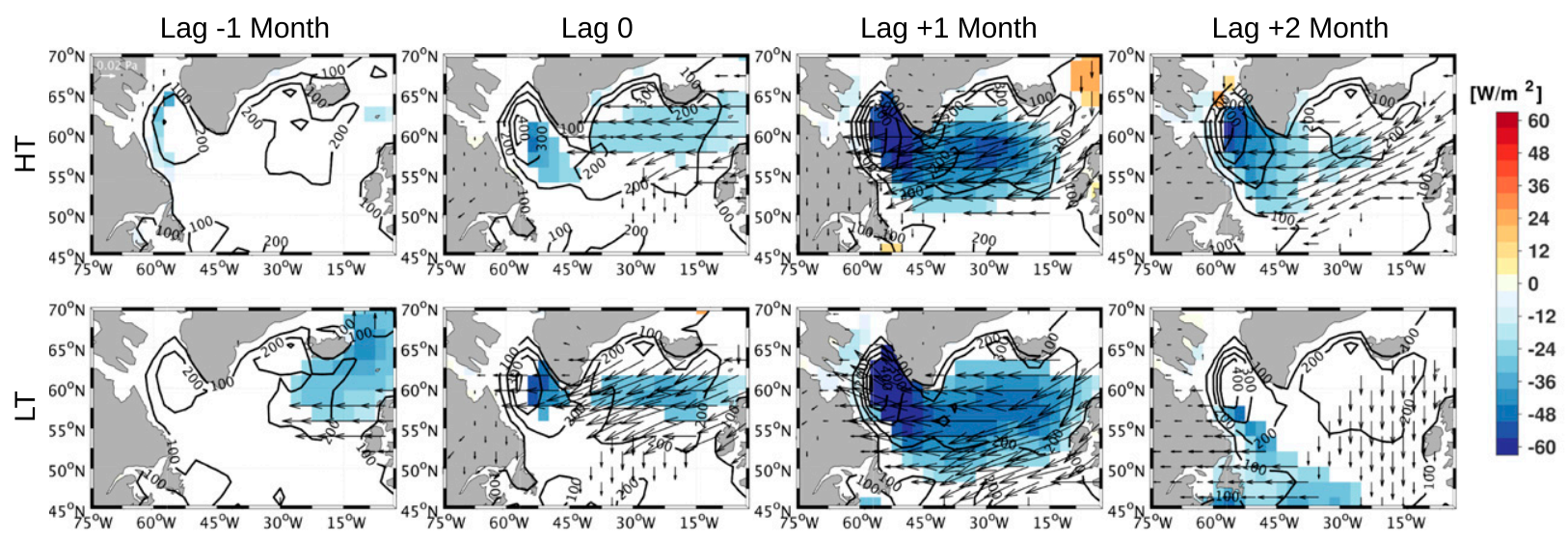

b) Maximum Mixed Layer Depth

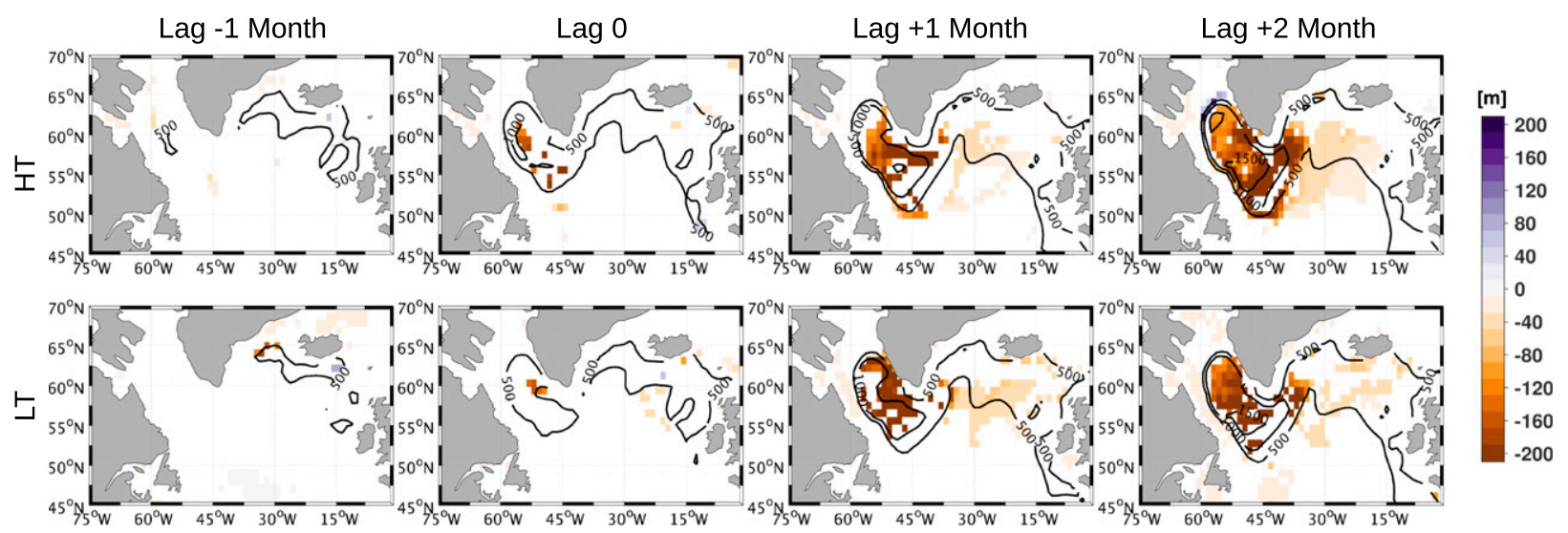

FIG. 4. NDJ SSW composites for the month prior to the SSW (lag -1 month), for the month in which the SSW occurs (lag 0), and for the two months following the SSW (lag +1 month and +2 months). For (a) surface turbulent (sensible plus latent, positive upward) heat flux anomalies in $\mathrm{W} \mathrm{m}^{-2}$ (shading), the corresponding climatology (contour lines), and wind stress anomalies in Pa (arrows, scale in figure). The contour interval is 6 (colors) and $100 \mathrm{~W} \mathrm{~m}^{-2}$ (contour lines). For (b) monthly maximum MLD anomalies in $\mathrm{m}$ (shading; reddish colors indicate shallower MLD than usual) and the corresponding climatology (contour lines). The contour interval is 20 (colors) and $500 \mathrm{~m}$ (contour lines). High-top results are shown above low-top model results. Negative contours are gray and dashed, positive contours are black. Colored areas are significant at the $95 \%$ level as computed from a bootstrapping test (see text for details)

with our results, found a stronger surface response in the high-top models. We find in addition a larger persistence of the surface signals in the high-top model, which could possibly have a larger influence on the ocean.

Following SSWs, the MLD is shallower than normal in the subpolar North Atlantic (Fig. 4b). The largest MLD anomalies are simulated in the Labrador Sea region and south of Greenland, consistent with the regions of strongest turbulent heat flux anomalies (Fig. 4a). Statistically significant MLD anomalies start to appear one month after the SSW onset $(\mathrm{lag}+1)$. MLD anomalies maximize at lag +2 , and again the high-top model shows slightly stronger and more persistent anomalies compared to the low-top model. Considering that the onset of the SSWs occurs between November and January, a lag of one month represents the months of December to February and a lag of two months, when the signal is even stronger, the months of January to March. Deep convection takes place in late winter and early spring; shallowing the MLD during this time of year may weaken North Atlantic Deep Water formation and thus the AMOC. Because of the relatively short simulations (150 years), we do not investigate the direct response of the AMOC here, but refer to earlier studies that report that a weak (strong) stratospheric polar vortex could weaken (strengthen) the AMOC with a time delay of a few years (Manzini et al. 2012; Reichler et al. 2012).

In summary, statistically significant influences of major NDJ SSWs on the North Atlantic surface climate and upper-ocean variability are simulated in both models. They are slightly more pronounced and persistent in the 
HT

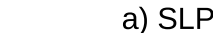

b) BSF c) $\mathrm{HF}$ d) SST
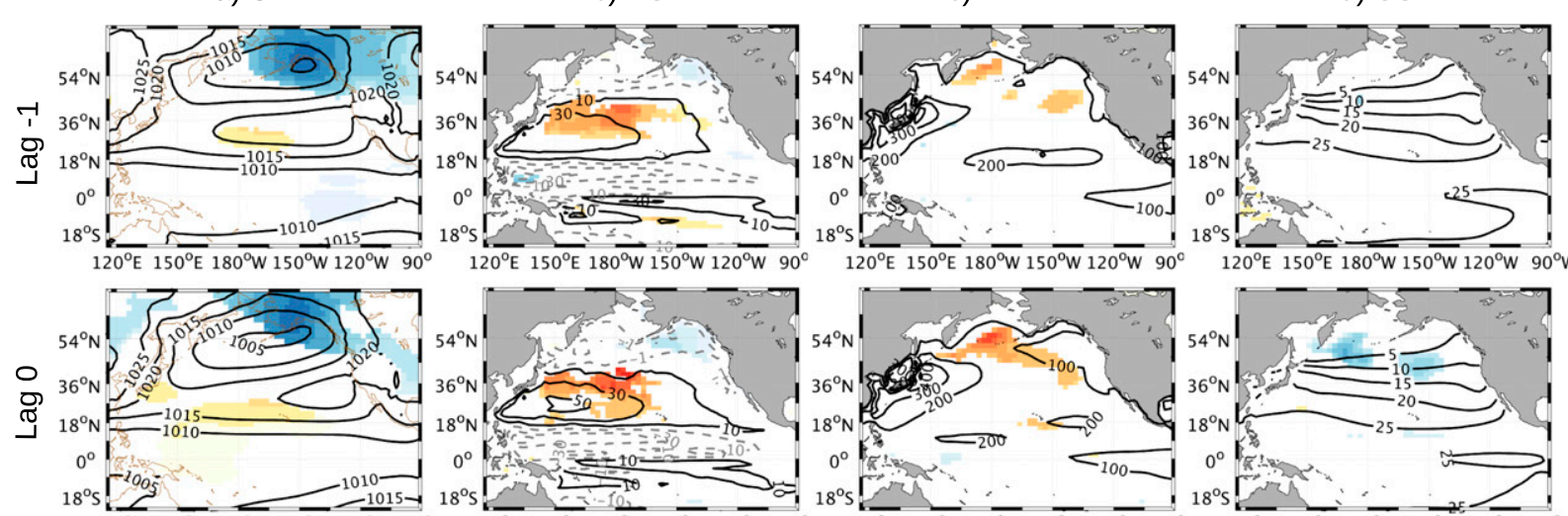

$18^{\circ} \mathrm{s} \Gamma^{2005}-1010-1015-1$
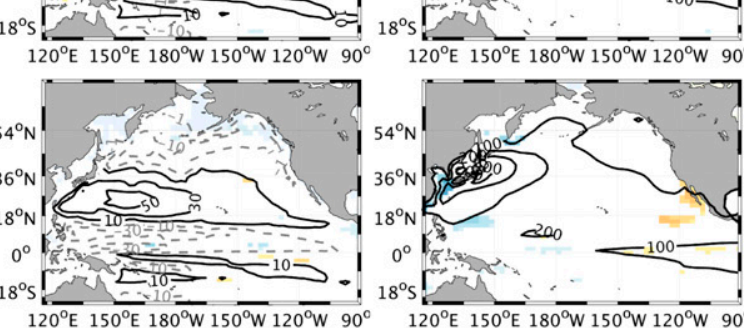

[Sv]
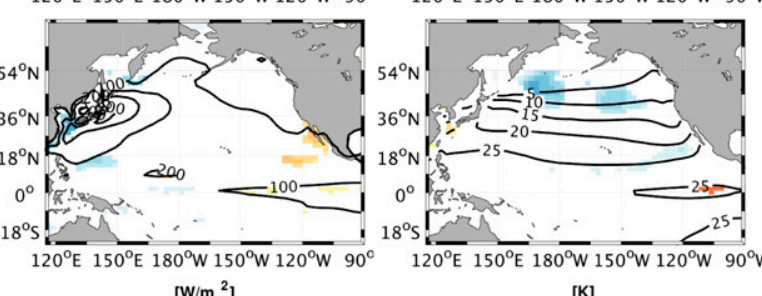

$\left[\mathrm{W} / \mathrm{m}^{2}\right]$

LT
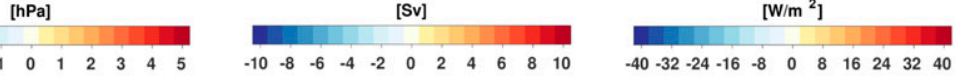

$120^{\circ} \mathrm{E} 150^{\circ} \mathrm{E} 180^{\circ} \mathrm{W} 150^{\circ} \mathrm{W} 120^{\circ} \mathrm{W} 90^{\circ} \mathrm{W}$

[K]
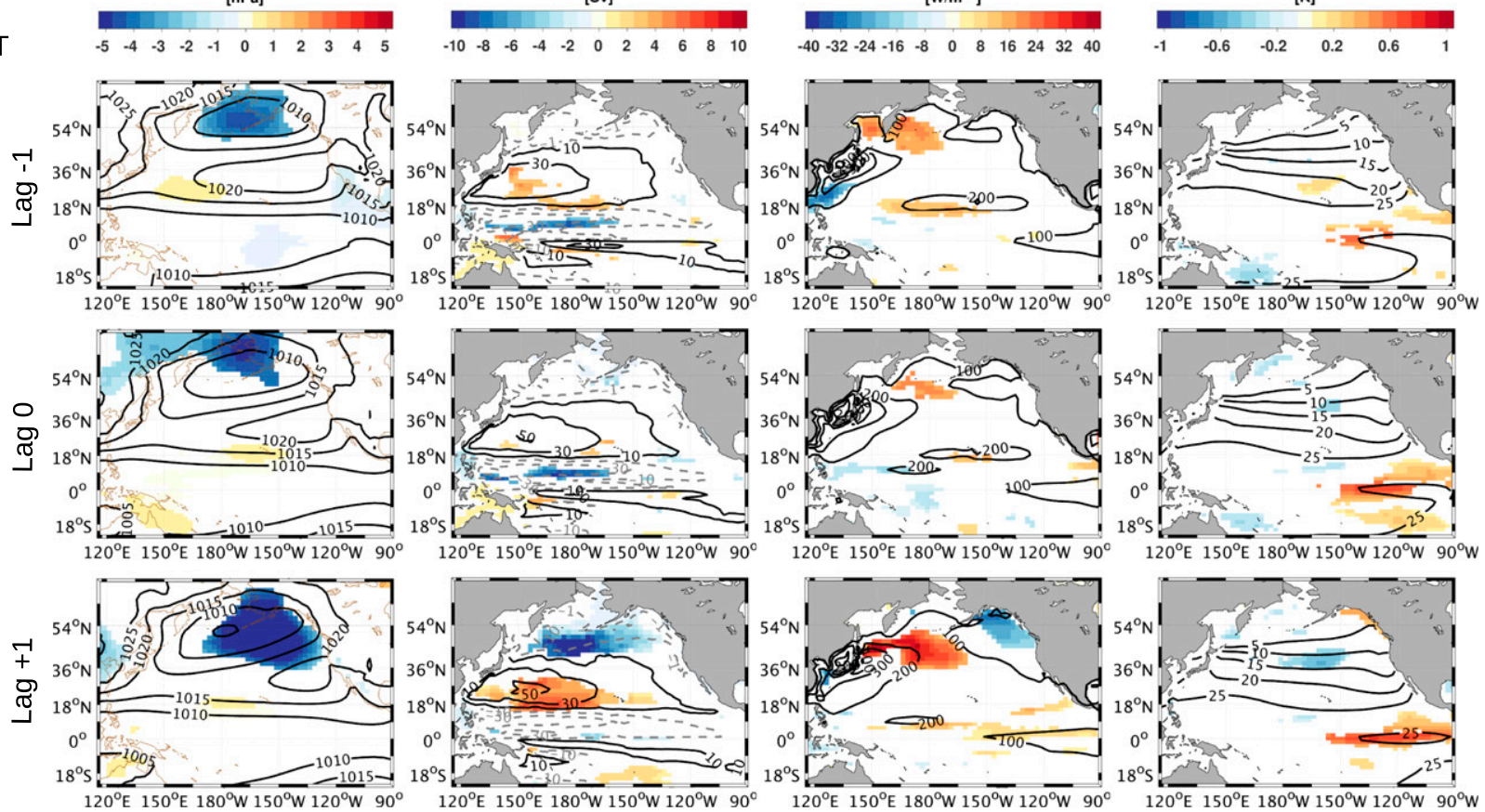

FIG. 5. NDJ SSW composites as in Fig. 4, but with emphasis on the Pacific region for (a) SLP in hPa, (b) BSF in Sv $\left(1 \mathrm{~Sv} \equiv 10^{6} \mathrm{~m}^{3} \mathrm{~s}^{-1}\right)$, (c) turbulent (sensible plus latent) heat flux in $\mathrm{W} \mathrm{m}^{-2}$, and (d) SST in K. High-top model results are shown above low-top model results. Shading shows the anomalies of the respective fields before (lag -1 month), during (lag 0$)$, and after (lag +1 month) a SSW, while contour lines show the respective climatological fields (positive: black and solid, negative: gray and dashed; the contour interval differs among variables and is indicated in the figure). Colored areas indicate statistical significance at the $95 \%$ level after a bootstrapping test.

high-top model as compared to the low-top model. In both model configurations, a major SSW is followed by anomalies typical for a negative NAO phase, which have the potential to weaken the AMOC via well-known mechanisms.

\section{d. The Pacific Ocean}

Figure 5 depicts anomalies of selected variables over the Pacific before, during, and after NDJ SSWs. The strengthening of the Aleutian low (Fig. 5a) prior to and 
during the onset of NDJ SSWs is associated with wind stress curl anomalies (not shown) that influence the gyre circulation, as indicated by the barotropic streamfunction (BSF; Fig. 5b). The signature of the BSF differs between the models. In the high-top model, there is a pronounced northward extension of the subtropical gyre, which is not the case for the low-top model. Enhanced turbulent heat flux from the ocean to the atmosphere in the northern North Pacific (positive anomalies; Fig. 5c) is found in both models and can be largely explained by the surface wind changes implied by the SLP anomalies (Fig. S1 in the online supplemental material), which is consistent with the study of Cayan (1992). The negative SST anomalies in the midlatitudes (Fig. 5d) are a result of this enhanced oceanic heat loss. We find these characteristics in both models before and during the SSW onset, but they differ in position and are more pronounced in the hightop model.

As discussed above, the largest discrepancies between the low-top and the high-top model are found one month after the SSW (lag +1), with the low-top model simulating a significant strengthening of the Aleutian low (Fig. 5a) that is seen neither in the hightop model nor in observations. This anomalous Aleutian low signature in the low-top model is associated with an intensification of both the subtropical and the subpolar gyre (inferred from the BSF; Fig. 5b). At lag +1 , the strongest heat flux anomalies (Fig. 5c) are also found in the low-top model, characterized by anomalously strong oceanic heat loss in the central North Pacific and reduced oceanic heat loss off the coast of Alaska. These heat flux anomalies lead to negative SST anomalies in the central North Pacific and to positive SST anomalies off the northwest coast of the North American continent (Fig. 5d), which is reminiscent of the SST signature during a positive PDO phase. Noteworthy also is the El Niño-like SST signal that develops in the tropical Pacific during the SSW in the low-top model. Westerly wind anomalies at the equator (supplemental Fig. S1) weaken the prevailing trade winds, which leads to a positive SST anomaly (Fig. 5d) due to reduced equatorial upwelling.

The different positioning and particularly the strengthening of the Aleutian low after NDJ SSWs in the low-top model leads to statistically significant differences in the surface and subsurface signals of the Pacific Ocean in the SSW composite compared to those in the high-top model (Fig. 5). In observations, the Aleutian low region is either characterized by a weakening or by no significant change after SSWs (e.g., Baldwin and Dunkerton 2001; Limpasuvan et al. 2004;
TABLE 2. The number of SSWs and the associated ENSO condition based on the Niño-3.4 index for the high-top and low-top model. Numbers are given for the NDJ season we mainly consider in this publication and for the whole winter season for a better comparison to other publications.

\begin{tabular}{lcr}
\hline \hline & \multicolumn{2}{l}{ Number of SSW in NDJ (NDJFM) } \\
\cline { 2 - 3 } ENSO state & High top & Low top \\
\hline El Niño & $14(23)$ & $10(16)$ \\
La Niña & $13(27)$ & $1(10)$ \\
Neutral ENSO & $14(20)$ & $11(19)$ \\
\hline
\end{tabular}

Charlton and Polvani 2007; Lehtonen and Karpechko 2016; Butler et al. 2017). The behavior of the Aleutian low following major SSWs is thus better captured in the high-top model.

It is well known that the Aleutian low region is also influenced by the conditions in the tropical Pacific. El Niño conditions strengthen the Aleutian low, whereas La Niña conditions weaken it. We therefore have a closer look at the distribution of ENSO states in the SSW composites derived from the two models (Table 2). Whereas La Niña, El Niño, and neutral ENSO conditions occur at similar rates during NDJ SSWs in the high-top model (El Niño: $34.1 \%$, La Niña: $31.8 \%$, neutral ENSO: $34.1 \%$ ), there is a strong asymmetry in the low-top model (El Niño: $45.5 \%$, La Niña: $4.5 \%$, neutral ENSO: 50\%). Here, almost all SSWs occur either during neutral ENSO or during El Niño conditions. Only one SSW occurs during La Niña conditions. Butler and Polvani (2011) demonstrated from reanalysis data that the probability for SSWs to occur during El Niño conditions is as large as during La Niña conditions, but only half as large during neutral ENSO conditions. Compared to these figures, the number of SSWs during neutral ENSO conditions is too high in both models investigated here. Part of this difference is attributed to the fact that we only consider NDJ SSWs. When considering the extended winter season [November-March (NDJFM)], the number of SSWs occurring during either El Niño or La Niña conditions increases relative to that during neutral ENSO conditions (numbers in parenthesis in Table 2). Regarding the ratio of SSWs during El Niño and SSWs during La Niña winters, the high-top model performs better than the low-top model. In the high-top model, the almost equal number of El Niño and La Niña winters in the SSW composite cancels their opposite effects on the Aleutian low (Butler et al. 2014). In the SSW composite derived from the low-top model, the virtually absent La Niña influence leads to an overrepresentation of the El Niño signal on the Aleutian low. We note that these differences between the 
high-top model and low-top model NDJ SSW composites remain when considering the whole winter season (not shown).

\section{The impact of the representation of the stratosphere}

We summarize the major differences in the behavior of the high-top and the low-top model as follows:

The high-top model

- better represents frequency and timing of SSWs and

- better captures the descent of anomalies following SSWs, which leads to more persistent NAO-like anomalies in the North Atlantic.

The low-top model

- shows a more persistent response in the North Pacific region, characterized by an anomalously strong Aleutian low one month after the SSW onset and

- exhibits a tendency for SSWs to occur during El Niño conditions rather than during La Niña conditions.

In this section, we address the reasons for these differences.

\section{a. Climatological differences}

Compared to the high-top model, the low-top model simulates a stronger mean stratospheric and weaker and slightly northward-shifted mean tropospheric jet in NDJ (Fig. 6a), which qualitatively agrees with a study by Sassi et al. (2010) using older versions of CAM and WACCM (see supplemental material for a more detailed comparison). The stronger stratospheric westerlies in the low-top model hinder upward planetary wave propagation (Charney and Drazin 1961), suggesting that a larger upward wave forcing is needed to sufficiently decelerate the westerlies to enable SSW development.

A hint for stronger planetary wave forcing in the lowtop model is the larger amplitude of the climatological wave-1 in the mid- to high-latitude stratosphere compared to the high-top model (supplemental Fig. S2a). Since wave-1 dominates the climatological quasi-stationary planetary wave signature (e.g., Lubis et al. 2016), we concentrate the investigation of planetary-scale wave behavior to this wavenumber. The phase of wave-1 (supplemental Fig. S2b) indicates a westward tilt with height in both NCAR models in the stratosphere poleward of about $30^{\circ} \mathrm{N}$, which is associated with upward wave propagation. In the low-top model, the westward tilt with height decreases toward higher latitudes. This feature was attributed to anomalous wave reflection close to the model lid in the older version of a) NDJ zonal mean wind

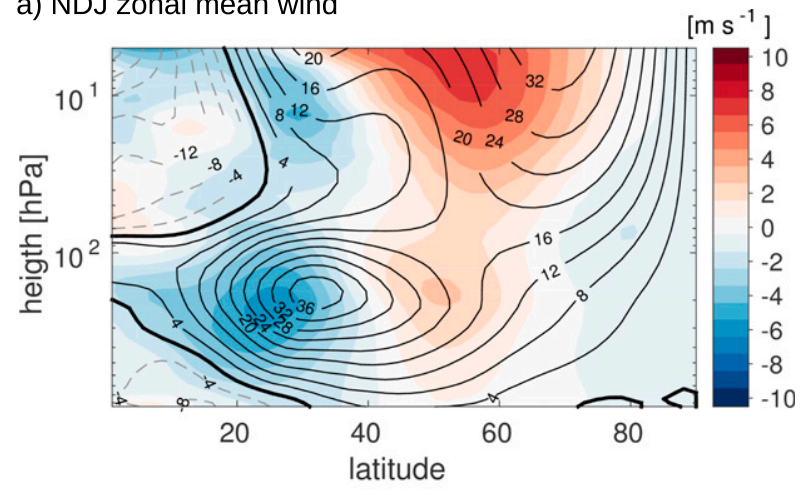

b) lagged SVD correlation
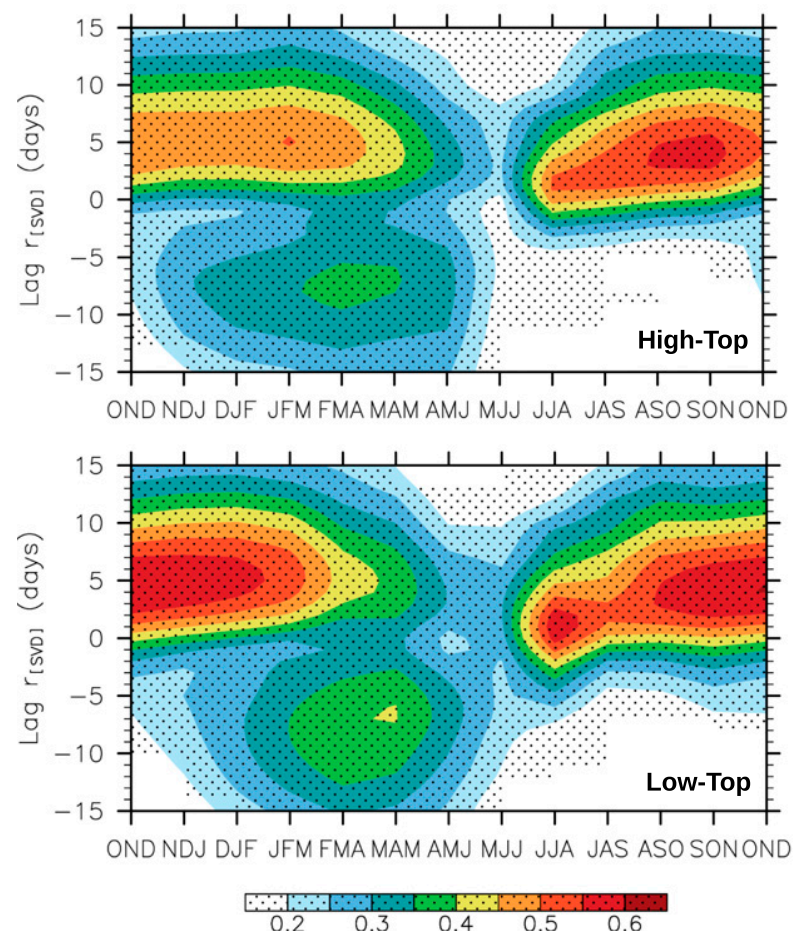

FIG. 6. (a) NDJ zonal-mean zonal wind. Contours show the climatology of the high-top model. Color shading indicates the difference low-top minus high-top model. All values as given in $\mathrm{m} \mathrm{s}^{-1}$. The contour line interval is $4 \mathrm{~m} \mathrm{~s}^{-1}$, the interval of the color shading is $1 \mathrm{~m} \mathrm{~s}^{-1}$. (b) Climatological 3-month overlapping periods of lagged SVD correlations between wave- $1 \mathrm{GPH}$ anomalies at 10 and $500 \mathrm{hPa}$ for the high-top and low-top model. For both models, 150 years of daily data were used for the analysis. See text for more details on the method. Negative (positive) lags represent stratospheric (tropospheric) lead. Stippling indicates significance at the $99 \%$ level.

CAM (Sassi et al. 2010). It is associated with stronger Eliassen-Palm (EP) flux divergence close to the model lid and therefore also with stronger westerly acceleration and strengthening of the PNJ. We find a qualitatively similar but weaker behavior in the newer CAM version (supplemental Figs. S2c,d) and conclude that spurious wave behavior close to the low-top model top 

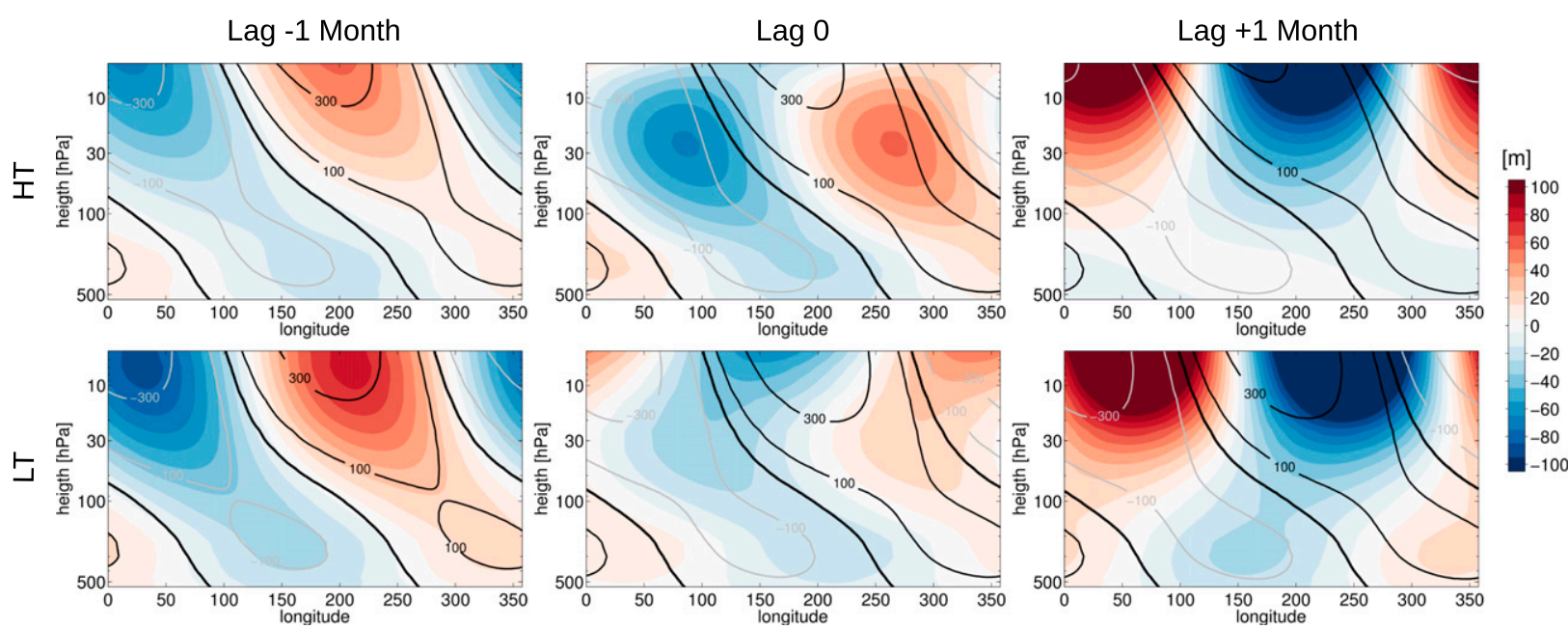

FIG. 7. NDJ SSW composites for the wave-1 component of eddy GPH anomalies (shading) and climatological fields (contours; positive: black, negative: gray; zero contour is bold) in $\mathrm{m}$, averaged over $40^{\circ}-60^{\circ} \mathrm{N}$ before (lag -1 month), during (lag 0 ), and after an SSW (lag +1 month) for the (top) high-top model and (bottom) low-top model.

contributes to the differences in the stratospheric polar vortex strength between the models.

The strength of the PNJ influences vertically propagating planetary waves. To investigate the wave propagation behavior in the high-top and low-top model in more detail, we use time-lagged singular value decomposition (SVD) correlation analysis, which is based on studies by Perlwitz and Harnik (2003) and Lubis et al. (2016). Using the SVD technique, the leading pattern of covariance between one stratospheric $(10 \mathrm{hPa})$ and one tropospheric level $(500 \mathrm{hPa})$ was computed for wave-1 GPH anomalies at different lags (stratospheric level lagging/leading from -15 to +15 days). This time-lagged SVD analysis was carried out for overlapping 3-month seasons to capture the seasonal characteristics. Correlations between the time coefficients of the leading SVD pattern were determined to evaluate the upward and downward wave coupling characteristics for the high- and the low-top model [Fig. 6b; see Lubis et al. (2016) for more details]. Negative (positive) lags indicate that the stratospheric (tropospheric) wave field is leading. Overall, correlations in the low-top model (Fig. 6b) are higher than in the hightop model for both stratospheric and tropospheric leads, suggesting stronger upward and downward planetary wave coupling in the low-top model. Stronger upward wave propagation (positive lags) introduces additional variability into the stratosphere in the low-top model that from time to time facilitates the emergence of major SSWs despite the stronger westerly mean flow.

\section{b. SSW preconditioning and evolution}

The differences in the mean state already hint at why the representation of SSWs and their impacts differs between the high-top and low-top model. The low-top model is characterized by a stronger PNJ during NDJ, which hinders SSW development. This is consistent with the lower frequency of SSWs in the low-top model in comparison to the high-top model or observations (Fig. 2). A larger planetary wave forcing as shown in the climatological mean (Fig. 6) is necessary in the low-top model to enable the emergence of SSWs and could be achieved by a strengthening of the Aleutian low.

To test this hypothesis, we calculated lagged SSW composites of the anomalies and climatological values of the eddy GPH wave- 1 component averaged over $40^{\circ}$ $60^{\circ} \mathrm{N}$ as a function of height and longitude (Fig. 7). The region of $40^{\circ}-60^{\circ} \mathrm{N}$ was chosen as it represents the latitude range of the Aleutian low in the North Pacific (Fig. 5). When the climatological wave and its anomalies agree (disagree) in sign, the anomalies enhance (diminish) the climatological wave, which is referred to as "positive (negative) interference." It can be inferred from Fig. 7 that the climatological wave-1 structure (contour lines) is characterized by a westward tilt with height at all lags, which is less pronounced in the low-top model close to the model lid in agreement with the difference in the phase tilt discussed previously. This indicates that upward wave propagation dominates in both models from October until February. One month before the onset of the SSW (Fig. 7; lag -1), the climatological structure is enhanced by wave- $1 \mathrm{GPH}$ anomalies (color shading) in both models (positive interference), which results in enhanced upward wave propagation as expected prior to a large disturbance of the stratospheric polar vortex. The negative GPH anomaly at about $500 \mathrm{hPa}$ in the longitude range of 
$180^{\circ}-220^{\circ} \mathrm{E}$ is consistent with a stronger Aleutian low. A better alignment of GPH anomalies and the climatology lead to stronger positive interference in the low-top model. This supports the assumption that an SSW in the low-top model is preceded by stronger upward wave forcing in the Aleutian low region relative to the hightop model (Fig. 7; lag -1). This can be confirmed by the vertical component of the EP-flux vector (Fz; supplemental Fig. S3) showing a stronger upward planetary wave forcing in the latitude band of the Aleutian low $\left(40^{\circ}-60^{\circ} \mathrm{N}\right)$ preceding SSWs in the low-top model compared to the high-top model.

At the time of the SSW onset (Fig. 7; lag 0), positive interference between the wave- 1 anomalies and the climatological stationary wave pattern weakens in both models. The anomalies start to tilt eastward with height in the middle and upper stratosphere, especially in the low-top model, leading to negative interference with the climatological wave field. This indicates a decrease in upward wave propagation in that region, that is, anomalous downward wave propagation. This signal is stronger in the low-top model and might be influenced by the different wave behavior at the lower model lid, as suggested by the climatological mean (section $4 \mathrm{a}$ ).

One month after the SSW onset (Fig. 7; lag +1) negative interference, that is, reduced upward wave propagation, dominates in the stratosphere in both models. In contrast to the high-top model, positive interference in the Aleutian low region in the troposphere is still supporting upward wave propagation in the lowtop model.

In summary, SSWs in the low-top model are preceded by a longer lasting and stronger upward wave propagation compared to the high-top model. This is required because of the stronger PNJ in the low-top model. El Niño events favor the deepening of the Aleutian low and therefore facilitate upward planetary wave forcing. This may explain why more SSWs occur during El Niño conditions than during La Niña conditions in the low-top model composite. It surely is very important to have this extra source of wave activity in the low-top model to enable SSWs. Nevertheless, there is about an equal number of SSWs occurring during neutral ENSO and El Niño conditions (Table 2). This implies that other factors also contribute to the preconditioning of SSWs.

\section{c. Neutral ENSO}

To separate the impact of ENSO from the tropospheric SSW signal, we will now consider only those SSWs that evolve during neutral ENSO conditions. Restricting the analysis to neutral ENSO winters neglects the stratospheric El Niño pathway (e.g., Ineson and Scaife 2009). However, neutral ENSO composites may be still the best possibility to detect the ENSOundisturbed SSW downward influence.

Neutral ENSO SSW composites for lag +1 are depicted in Fig. 8. They are composed of 14 events for the high-top model and 11 events for the low-top model. The most striking difference of the stronger Aleutian low in the low-top model in the "full" SSW composite (Fig. 3g) no longer exists for the neutral ENSO composite (Fig. 8a), suggesting that it was due to the dominance of El Niño. The negative NAO-like SLP signal over the Atlantic region under neutral ENSO conditions only is strong and statistically significant in the high-top model after the SSW onset (Fig. 8a), which indicates that the high-top model better simulates stratospheretroposphere coupling during neutral ENSO conditions. This has implications for the response of the North Atlantic Ocean: wind stress, heat flux, and MLD anomalies also are more prominent in the high-top model at this stage (Figs. 8b,c). We therefore conclude that during neutral ENSO conditions, the impact of SSWs on deep convection in the subpolar North Atlantic Ocean is stronger in the high-top model. The NAO-like signal in the "full" composite (Fig. 4) calculated from the low-top model is almost absent in the neutral ENSO composite. This suggests that a large part of the signal shown for the low-top model in Fig. 4 is strongly connected to El Niño and not solely due to SSWs.

\section{Conclusions}

In this study we investigated the connection between major stratospheric sudden warmings (SSWs) in NovemberJanuary (NDJ) and surface climate anomalies in the North Atlantic and North Pacific regions. We also discuss the implications of these anomalies for the ocean circulation in the two basins. A special focus is on the comparison between a high-top model configuration, CESM1(WACCM), and a low-top model configuration, CCSM4-WSET, of the NCAR climate model family in order to investigate the importance of the representation of the stratosphere for surface climate variability. Only preindustrial control simulations are considered with the two models, each 150 years long. The main findings can be summarized as follows:

- The representation of SSWs in terms of frequency, downward propagation, and SLP response is closer to observations and more persistent in the high-top model compared to the low-top model (Figs. 1-3).

- The lower SSW frequency in the low-top model is attributed to stronger mean-state westerlies over the winter stratosphere (Fig. 6), which requires stronger planetary wave forcing to initiate SSWs (Figs. 6, 7). 


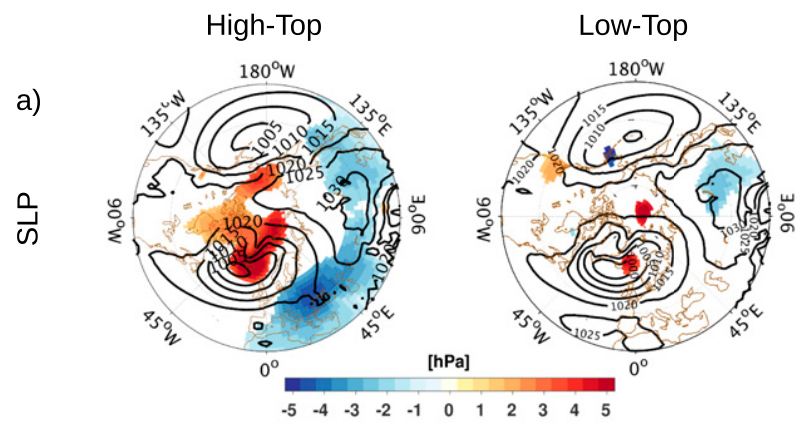

b)

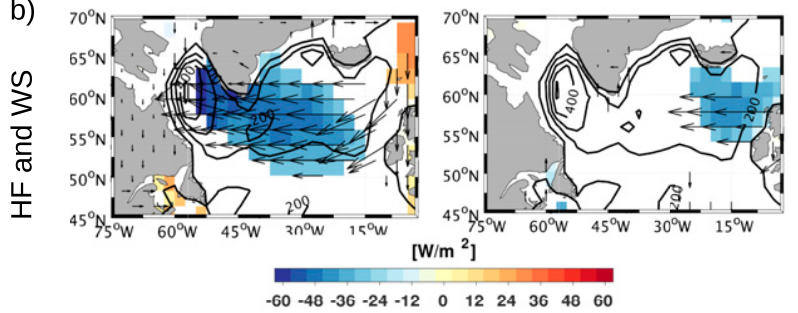

c)

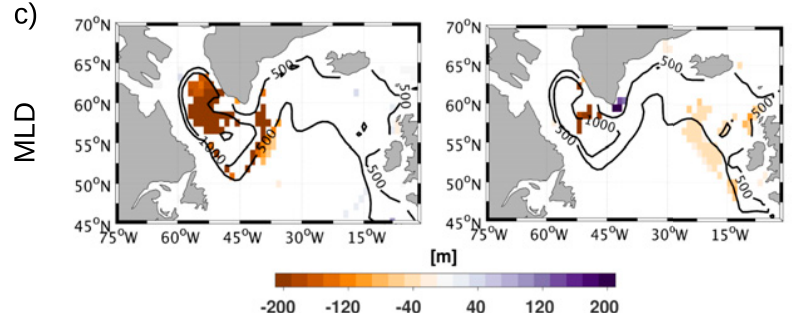

FIG. 8. NDJ SSW composites of (a) SLP in hPa, (b) turbulent heat flux in $\mathrm{W} \mathrm{m}^{-2}$, and wind stress in Pa, as well as (c) maximum MLD anomalies in $\mathrm{m}$ (shading, respectively, arrows for wind stress, reference arrow in Fig. 4) and the corresponding climatological fields (contour lines) for the high-top and low-top model for the month following the SSW (lag +1 month). The composite only includes SSWs that occur during neutral ENSO conditions. Colored areas and the arrows indicated are significant at the $90 \%$ level as computed from a bootstrapping test (see text for details).

- The stronger Aleutian low in the low-top model favors stronger upward wave propagation associated with positive interference between wave-1 geopotential height $(\mathrm{GPH})$ anomalies and the climatological wave structure (Fig. 7).

- SSWs are favored during El Niño conditions in the low-top model. This leads to an unrealistically high abundance of El Niño events in the low-top model SSW composite favoring the strengthening of the Aleutian low (Table 2).

- Over the North Pacific Ocean, only SSW precursor effects (Fig. 5) but no SSW downward effects are detected (Fig. 8a).

- Over the North Atlantic Ocean, a clear negative NAO-like SLP signal is detected in both models (Fig. 3), which reduces oceanic heat loss (Fig. 4), leading to a shallower-than-normal maximum mixed layer depth (MLD) two months after the SSW (Fig. 4). The MLD anomalies are slightly stronger and more persistent in the high-top model.

- During neutral ENSO conditions, the NAO and MLD response following SSWs only is significant in the high-top model, suggesting that this model better simulates stratosphere-troposphere coupling (Fig. 8).

Our results confirm that there is a stratospheric influence on the North Atlantic Ocean that could possibly enable an impact on the AMOC as proposed by Reichler et al. (2012) and Manzini et al. (2012). Because of the restricted length of our simulations (150 years), we do not address the low-frequency variability of the AMOC. The significant difference in the number of SSWs between the hightop model and low-top model and the larger impact of neutral ENSO SSWs on North Atlantic MLD in the hightop model may result in a different AMOC response to SSWs between the models on longer time scales.

With our study, we confirm earlier findings that the surface response of SSWs is strongest in the North Atlantic region (e.g., Garfinkel et al. 2013; Hitchcock and Simpson 2014).

The observed differences in the climatological state between the two model versions and the connected planetary wave behavior, however, can have important consequences for the representation of surface climate variability, especially with regard to the regional influences of stratospheric variability. Our results demonstrate a better represented and more persistent SSW impact on the North Atlantic during neutral ENSO conditions in the high-top model. In the low-top model, the spurious persistence of the Aleutian low over the Pacific after SSWs is mainly due to the artifact that a large portion of the SSWs occur during El Niño conditions. We suggest that this overrepresentation of SSWs during El Niño conditions in the low-top model is favored by the poorer representation of the stratosphere. In particular, the stratospheric polar vortex is too strong and hence requires a stronger planetary wave forcing to initiate SSWs in that model. However, the stronger planetary wave forcing only is effective in generating the required upward wave propagation if the El Niño teleconnection pattern in the North Pacific (i.e., the Aleutian low) and the location of the SSW precursor region positively interfere (Garfinkel et al. 2012). A pattern correlation between these two effects in the two model configurations analyzed here reveals that the influence of El Niño on the SSW precursor region is indeed stronger in the low-top model (supplemental Fig. S4).

If the different SSW precursor regions are influenced by the representation of the stratosphere and whether the deficiencies in stratosphere-troposphere coupling during 
neutral ENSO conditions in the presented low-top model are reproducible in a larger low-top model ensemble and characteristic of other low-top models remains to be investigated.

Acknowledgments. We thank three anonymous reviewers for their constructive comments that helped to improve the manuscript substantially. This work was part of the Helmholtz-University Young Investigators Group NATHAN funded by the Helmholtz Association through the president's Initiative and Networking Fund and the GEOMAR Helmholtz-Centre for Ocean Research in Kiel. This study was also partly supported by the Belmont Forum's project InterDec. We thank the computing center at Kiel University for support and computer time. Special thanks go to Dr. Sandro Lubis for helpful discussions and suggestions on the planetary wave analysis.

\section{REFERENCES}

Ambaum, M. H. P., and B. J. Hoskins, 2002: The NAO tropospherestratosphere connection. J. Climate, 15, 1969-1978, https:// doi.org/10.1175/1520-0442(2002)015<1969:TNTSC >2.0.CO;2.

Andrews, D. G., J. R. Holton, and C. B. Leovy, 1987: Middle Atmosphere Dynamics. Academic Press, 489 pp.

Baldwin, M. P., and T. J. Dunkerton, 1999: Propagation of the Arctic Oscillation from the stratosphere to the troposphere. J. Geophys. Res., 104, 30 937-30 946, https://doi.org/10.1029/1999JD900445.

—, and —, 2001: Stratospheric harbingers of anomalous weather regimes. Science, 294, 581-584, https://doi.org/ 10.1126/science. 1063315 .

_- X. X. Cheng, and T. J. Dunkerton, 1994: Observed correlations between winter-mean tropospheric and stratospheric circulation anomalies. Geophys. Res. Lett., 21, 1141-1144, https://doi.org/10.1029/94GL01010.

—, D. B. Stephenson, D. W. J. Thompson, T. J. Dunkerton, A. J. Charlton, and A. O'Neill, 2003: Stratospheric memory and skill of extended-range weather forecasts. Science, 301, 636640, https://doi.org/10.1126/science.1087143.

Bancalá, S., K. Krüger, and M. Giorgetta, 2012: The preconditioning of major sudden stratospheric warmings. J. Geophys. Res., 117, D04101, https://doi.org/10.1029/ 2011JD016769.

Barriopedro, D., and N. Calvo, 2014: On the relationship between ENSO, stratospheric sudden warmings, and blocking. J. Climate, 27, 4704-4720, https://doi.org/10.1175/JCLI-D-13-00770.1.

Black, R. X., 2002: Stratospheric forcing of surface climate in the Arctic Oscillation. J. Climate, 15, 268-277, https://doi.org/ 10.1175/1520-0442(2002)015<0268:SFOSCI > 2.0.CO;2.

Blume, C., K. Matthes, and I. Horenko, 2012: Supervised learning approaches to classify sudden stratospheric warming events. J. Atmos. Sci., 69, 1824-1840, https://doi.org/10.1175/ JAS-D-11-0194.1.

Boville, B. A., 1984: The influence of the polar night jet on the tropospheric circulation in a GCM. J. Atmos. Sci., 41, 1132-1142, https://doi.org/10.1175/1520-0469(1984)041<1132: TIOTPN $>2.0 . \mathrm{CO} ; 2$

Butler, A. H., and L. M. Polvani, 2011: El Niño, La Niña, and stratospheric sudden warmings: A reevaluation in light of the observational record. Geophys. Res. Lett., 38, L13807, https:// doi.org/10.1029/2011GL048084.

- — - and C. Deser, 2014: Separating the stratospheric and tropospheric pathways of El Niño-Southern Oscillation teleconnections. Environ. Res. Lett., 9, 024014, https://doi.org/ 10.1088/1748-9326/9/2/024014.

_ J. P. Sjoberg, D. J. Seidel, and K. H. Rosenlof, 2017: A sudden stratospheric warming compendium. Earth Syst. Sci. Data, 9, 63-76, https://doi.org/10.5194/essd-9-63-2017.

Cayan, D. R., 1992: Latent and sensible heat flux anomalies over the northern oceans: Driving the sea surface temperature. J. Phys. Oceanogr., 22, 859-881, https://doi.org/10.1175/ 1520-0485(1992)022<0859:LASHFA $>2.0$. CO; 2.

Charlton, A. J., and L. M. Polvani, 2007: A new look at stratospheric sudden warmings. Part I: Climatology and modeling benchmarks. J. Climate, 20, 449-470, https://doi.org/10.1175/ JCLI3996.1; Corrigendum, 24, 5951, https://doi.org/10.1175/ JCLI-D-11-00348.1.

— namical variability in low-top versions of the CMIP5 models. J. Geophys. Res. Atmos., 118, 2494-2505, https:// doi.org/10.1002/jgrd.50125.

Charney, J. G., and P. G. Drazin, 1961: Propagation of planetaryscale disturbances from the lower into the upper atmosphere. J. Geophys. Res., 66, 83-109, https://doi.org/10.1029/ JZ066i001p00083.

Dee, D. P., and Coauthors, 2011: The ERA-Interim reanalysis: Configuration and performance of the data assimilation system. Quart. J. Roy. Meteor. Soc., 137, 553-597, https://doi.org/ 10.1002/qj.828.

de la Torre, L., R. R. Garcia, D. Barriopedro, and A. Chandran, 2012: Climatology and characteristics of stratospheric sudden warmings in the Whole Atmosphere Community Climate Model. J. Geophys. Res., 117, D04110, https://doi.org/10.1029/ 2011JD016840.

Eden, C., and T. Jung, 2001: North Atlantic interdecadal variability: Oceanic response to the North Atlantic Oscillation (1865-1997). J. Climate, 14, 676-691, https://doi.org/10.1175/ 1520-0442(2001)014<0676:NAIVOR >2.0.CO;2.

_ , and J. Willebrand, 2001: Mechanism of interannual to decadal variability of the North Atlantic circulation. J. Climate, 14, 2266-2280, https://doi.org/10.1175/1520-0442(2001)014<2266: MOITDV $>2.0 . \mathrm{CO} ; 2$.

Garcia, R. R., D. R. Marsh, D. E. Kinnison, B. A. Boville, and F. Sassi, 2007: Simulation of secular trends in the middle atmosphere, 1950-2003. J. Geophys. Res., 112, D09301, https:// doi.org/10.1029/2006JD007485.

Garfinkel, C. I., A. H. Butler, D. W. Waugh, M. M. Hurwitz, and L. M. Polvani, 2012: Why might stratospheric sudden warmings occur with similar frequency in El Niño and La Niña winters? J. Geophys. Res., 117, D19106, https://doi.org/ 10.1029/2012JD017777.

— D. W. Waugh, and E. P. Gerber, 2013: The effect of tropospheric jet latitude on coupling between the stratospheric polar vortex and the troposphere. J. Climate, 26, 2077-2095, https://doi.org/10.1175/JCLI-D-12-00301.1.

Hansen, F., K. Matthes, C. Petrick, and W. Wang, 2014: The influence of natural and anthropogenic factors on major stratospheric sudden warmings. J. Geophys. Res. Atmos., 119, 8117-8136, https://doi.org/10.1002/2013JD021397.

Hartmann, D. L., J. M. Wallace, V. Limpasuvan, D. W. J. Thompson, and J. R. Holton, 2000: Can ozone depletion and global warming interact to produce rapid climate change? 
Proc. Natl. Acad. Sci. USA, 97, 1412-1417, https://doi.org/ 10.1073/pnas.97.4.1412.

Haynes, P. H., M. E. McIntyre, T. G. Shepherd, C. J. Marks, and K. P. Shine, 1991: On the "downward control" of extratropical diabatic circulations by eddy-induced mean zonal forces. J. Atmos. Sci., 48, 651-678, https://doi.org/10.1175/ 1520-0469(1991)048<0651:OTCOED>2.0.CO;2.

Heuzé, C., 2017: North Atlantic Deep Water formation and AMOC in CMIP5 models. Ocean Sci., 13, 609-622, https:// doi.org/10.5194/os-13-609-2017.

Hitchcock, P., and I. R. Simpson, 2014: The downward influence of stratospheric sudden warmings. J. Atmos. Sci., 71, 6856-3876, https://doi.org/10.1175/JAS-D-14-0012.1.

Horel, J. D., and J. M. Wallace, 1981: Planetary-scale atmospheric phenomena associated with the Southern Oscillation. Mon. Wea. Rev., 109, 813-829, https://doi.org/10.1175/ 1520-0493(1981)109<0813:PSAPAW > 2.0.CO;2.

Hurrell, J. W., 1995: Decadal trends in the North Atlantic Oscillation: Regional temperatures and precipitation. Science, 269, 676-679, https://doi.org/10.1126/science.269.5224.676.

_ Y. Yushnir, G. Ottersen, and M. Visbeck, 2003: An overview of the North Atlantic Oscillation. The North Atlantic Oscillation: Climatic Significance and Environmental Impact, Geophys. Monogr., Vol. 134, Amer. Geophys. Union, 1-35, https:// doi.org/10.1029/134GM01.

_- and Coauthors, 2013: The Community Earth System Model: A framework for collaborative research. Bull. Amer. Meteor. Soc., 94, 1339-1360, https://doi.org/10.1175/ BAMS-D-12-00121.1.

Hurwitz, M. M., P. A. Newman, and C. I. Garfinkel, 2012: On the influence of North Pacific sea surface temperature on the Arctic winter climate. J. Geophys. Res., 117, D19110, https:// doi.org/10.1029/2012JD017819.

Ineson, S., and A. A. Scaife, 2009: The role of the stratosphere in the European climate response to El Niño. Nat. Geosci., 2, 3236, https://doi.org/10.1038/ngeo381.

Jadin, E. A., K. Wei, Y. A. Zyulyaeva, W. Chen, and L. Wang, 2010: Stratospheric wave activity and the Pacific decadal oscillation. J. Atmos. Sol.-Terr. Phys., 72, 1163-1170, https:// doi.org/10.1016/j.jastp.2010.07.009.

Kidston, J., A. A. Scaife, S. C. Hardiman, D. M. Mitchell, N. Butchart, M. P. Baldwin, and L. J. Gray, 2015: Stratospheric influence on tropospheric jet streams, storm tracks and surface weather. Nat. Geosci., 8, 433-440, https://doi.org/10.1038/ngeo2424.

Kinnison, D. E., and Coauthors, 2007: Sensitivity of chemical tracers to meteorological parameters in the MOZART-3 chemical transport model. J. Geophys. Res., 112, D20302, https://doi.org/10.1029/2006JD007879.

Kodera, K., H. Mukougawa, P. Maury, M. Ueda, and C. Claud, 2016: Absorbing and reflecting sudden stratospheric warming events and their relationship with tropospheric circulation. J. Geophys. Res. Atmos., 121, 80-94, https://doi.org/10.1002/2015JD023359.

Kolstad, E. W., and A. J. Charlton-Perez, 2011: Observed and simulated precursors of stratospheric polar vortex anomalies in the Northern Hemisphere. Climate Dyn., 37, 1443-1456, https://doi.org/10.1007/s00382-010-0919-7.

Kren, A. C., D. R. Marsh, A. K. Smith, and P. Pilewskie, 2016: Wintertime Northern Hemisphere response in the stratosphere to the Pacific decadal oscillation using the Whole Atmosphere Community Climate Model. J. Climate, 29, 10311049, https://doi.org/10.1175/JCLI-D-15-0176.1.

Kunz, T., and R. J. Greatbatch, 2013: On the northern annular mode surface signal associated with stratospheric variabil- ity. J. Atmos. Sci., 70, 2103-2118, https://doi.org/10.1175/ JAS-D-12-0158.1.

Kuroda, Y., and K. Kodera, 1999: Role of planetary waves in the stratosphere-troposphere coupled variability in the Northern Hemisphere winter. Geophys. Res. Lett., 26, 2375-2378, https:// doi.org/10.1029/1999GL900507.

Latif, M., and N. S. Keenlyside, 2011: A perspective on decadal climate variability and predictability. Deep-Sea Res. II, 58, 1880-1894, https://doi.org/10.1016/j.dsr2.2010.10.066.

Lavender, K. L., R. E. Davis, and W. B. Owens, 2002: Observations of open-ocean deep convection in the Labrador Sea from subsurface floats. J. Phys. Oceanogr., 32, 511-526, https://doi.org/ 10.1175/1520-0485(2002)032<0511:OOOODC >2.0.CO;2.

Lee, Y.-Y., and R. X. Black, 2015: The structure and dynamics of the stratospheric northern annular mode in CMIP5 simulations. J. Climate, 28, 86-107, https://doi.org/10.1175/ JCLI-D-13-00570.1.

Lehtonen, I., and A. Y. Karpechko, 2016: Observed and modeled tropospheric cold anomalies associated with sudden stratospheric warmings. J. Geophys. Res. Atmos., 121, 1591-1610, https://doi.org/10.1002/2015JD023860.

Limpasuvan, V., and D. L. Hartmann, 2000: Wave-maintained annular modes of climate variability. J. Climate, 13, 44144429, https://doi.org/10.1175/1520-0442(2000)013<4414: WMAMOC $>2.0 . \mathrm{CO} ; 2$.

— - D. W. J. Thompson, and D. L. Hartmann, 2004: The life cycle of the Northern Hemisphere sudden stratospheric warmings. J. Climate, 17, 2584-2596, https://doi.org/10.1175/ 1520-0442(2004)017<2584:TLCOTN>2.0.CO;2.

Lubis, S. W., K. Matthes, N.-E. Omrani, N. Harnik, and S. Wahl, 2016: Influence of the quasi-biennial oscillation and sea surface temperature variability on downward wave coupling in the Northern Hemisphere. J. Atmos. Sci., 73, 1943-1965, https://doi.org/10.1175/JAS-D-15-0072.1.

Mantua, N. J., S. R. Hare, Y. Zhang, J. M. Wallace, and R. C. Francis, 1997: A Pacific interdecadal climate oscillation with impacts on salmon production. Bull. Amer. Meteor. Soc., 78 , 1069-1079, https://doi.org/10.1175/1520-0477(1997)078<1069: APICOW $>2.0 . \mathrm{CO} ; 2$.

Manzini, E., M. A. Giorgetta, M. Esch, L. Kornblueh, and E. Roeckner, 2006: The influence of sea surface temperatures on the northern winter stratosphere: Ensemble simulations with the MAECHAM5 model. J. Climate, 19, 3863-3881, https://doi.org/10.1175/JCLI3826.1.

, C. Cagnazzo, P. G. Fogli, A. Bellucci, and W. A. Müller, 2012: Stratosphere-troposphere coupling at inter-decadal time scales: Implications for the North Atlantic Ocean. Geophys. Res. Lett., 39, L05801, https://doi.org/10.1029/2011GL050771.

Marsh, D. R., M. J. Mills, D. E. Kinnison, J.-F. Lamarque, N. Calvo, and L. M. Polvani, 2013: Climate change from 1850 to 2005 simulated in CESM1(WACCM). J. Climate, 26, 7372 7391, https://doi.org/10.1175/JCLI-D-12-00558.1.

Martius, O., L. M. Polvani, and H. C. Davies, 2009: Blocking precursors to stratospheric sudden warming events. Geophys. Res. Lett., 36, L14806, https://doi.org/10.1029/2009GL038776.

Maycock, A. C., and P. Hitchcock, 2015: Do split and displacement sudden stratospheric warmings have different annular mode signatures? Geophys. Res. Lett., 42, $10943-10951$, https:// doi.org/10.1002/2015GL066754.

Neale, R. B., and Coauthors, 2010: Description of the NCAR Community Atmosphere Model (CAM 4.0). NCAR Tech. Note NCAR/TN-485+STR, 212 pp., www.cesm.ucar.edu/models/ ccsm4.0/cam/docs/description/cam4_desc.pdf. 
Perlwitz, J., and H.-F. Graf, 1995: The statistical connection between tropospheric and stratospheric circulation of the Northern Hemisphere in winter. J. Climate, 8, 22812295, https://doi.org/10.1175/1520-0442(1995)008<2281: TSCBTA $>2.0 . \mathrm{CO} ; 2$.

_ , and N. Harnik, 2003: Observational evidence of a stratospheric influence on the troposphere by planetary wave reflection. J. Climate, 16, 3011-3026, https://doi.org/10.1175/ 1520-0442(2003)016<3011:OEOASI >2.0.CO;2.

Philander, S. G. H., 1985: El Niño and La Niña. J. Atmos. Sci., 42, 2652-2662, https://doi.org/10.1175/1520-0469(1985)042<2652: ENALN $>2.0 . \mathrm{CO} ; 2$

Reichler, T., J. Kim, E. Manzini, and J. Kröger, 2012: A stratospheric connection to Atlantic climate variability. Nat. Geosci., 5, 783-787, https://doi.org/10.1038/ngeo1586.

Richter, J. H., F. Sassi, and R. R. Garcia, 2010: Toward a physically based gravity wave source parameterization in a general circulation model. J. Atmos. Sci., 67, 136-156, https://doi.org/ 10.1175/2009JAS3112.1.

Sassi, F., R. R. Garcia, D. Marsh, and K. W. Hoppel, 2010: The role of the middle atmosphere in simulations of the troposphere during Northern Hemisphere winter: Differences between high- and low-top models. J. Atmos. Sci., 67, 3048-3064, https://doi.org/10.1175/2010JAS3255.1.

Scherhag, R., 1952: Die explosionsartige Stratosphärenerwärmung des Spätwinters 1951/52. Ber. Dtsch. Wetterdienstes, 38, 51-63.

Shaw, T. A., and J. Perlwitz, 2010: The impact of stratospheric model configuration on planetary-scale waves in Northern Hemisphere winter. J. Climate, 23, 3369-3389, https://doi.org/ 10.1175/2010JCLI3438.1.

Sigmond, M., J. F. Scinocca, V. V. Kharin, and T. G. Shepherd, 2013: Enhanced seasonal forecast skill following stratospheric sudden warmings. Nat. Geosci., 6, 98-102, https://doi.org/10.1038/ngeo1698.

Song, Y., and W. A. Robinson, 2004: Dynamical mechanisms for stratospheric influences on the troposphere. J. Atmos. Sci., 61, 1711-1725, https://doi.org/10.1175/1520-0469(2004)061<1711: DMFSIO $>2.0 . \mathrm{CO} ; 2$.
Taguchi, M., and D. L. Hartmann, 2006: Increased occurrence of stratospheric sudden warmings during El Niño as simulated by WACCM. J. Climate, 19, 324-332, https://doi.org/10.1175/ JCLI3655.1.

Thompson, D. W. J., and J. M. Wallace, 1998: The Arctic Oscillation signature in the wintertime geopotential height and temperature fields. Geophys. Res. Lett., 25, 1297-1300, https:// doi.org/10.1029/98GL00950.

— tion. Part I: Month-to-month variability. J. Climate, 13, 1000-1016, https://doi.org/10.1175/1520-0442(2000)013<1000: AMITEC $>2.0 . \mathrm{CO} ; 2$.

- M. P. Baldwin, and J. M. Wallace, 2002: Stratospheric connection to Northern Hemisphere wintertime weather: Implications for prediction. J. Climate, 15, 14211428, https://doi.org/10.1175/1520-0442(2002)015<1421: SCTNHW $>2.0$. CO;2; Corrigendum, 16, 2433, https://doi.org/ 10.1175/1520-0442(2003)16<2433:C >2.0.CO;2.

Trenberth, K. E., 1997: The definition of El Niño. Bull. Amer. Meteor. Soc., 78, 2771-2778, https://doi.org/10.1175/ 1520-0477(1997)078<2771:TDOENO > 2.0.CO;2.

_- G. W. Branstator, D. Karoly, A. Kumar, N.-C. Lau, and C. Ropelewski, 1998: Progress during TOGA in understanding and modeling global teleconnections associated with tropical sea surface temperatures. J. Geophys. Res., 103, 14 291-14 324, https://doi.org/10.1029/97JC01444.

Uppala, S. M., and Coauthors, 2005: The ERA-40 Re-Analysis. Quart. J. Roy. Meteor. Soc., 131, 2961-3012, https://doi.org/ 10.1256/qj.04.176.

von Storch, H., and F. W. Zwiers, 1999: Statistical Analysis in Climate Research. Cambridge University Press, 495 pp.

Walker, G. T., and E. W. Bliss, 1932: World weather V. Mem. Roy. Meteor. Soc., 4, 53-84.

Woo, S.-H., M.-K. Sung, S.-W. Son, and J.-S. Kug, 2015: Connection between weak stratospheric vortex events and the Pacific decadal oscillation. Climate Dyn., 45, 3481-3492, https:// doi.org/10.1007/s00382-015-2551-z. 